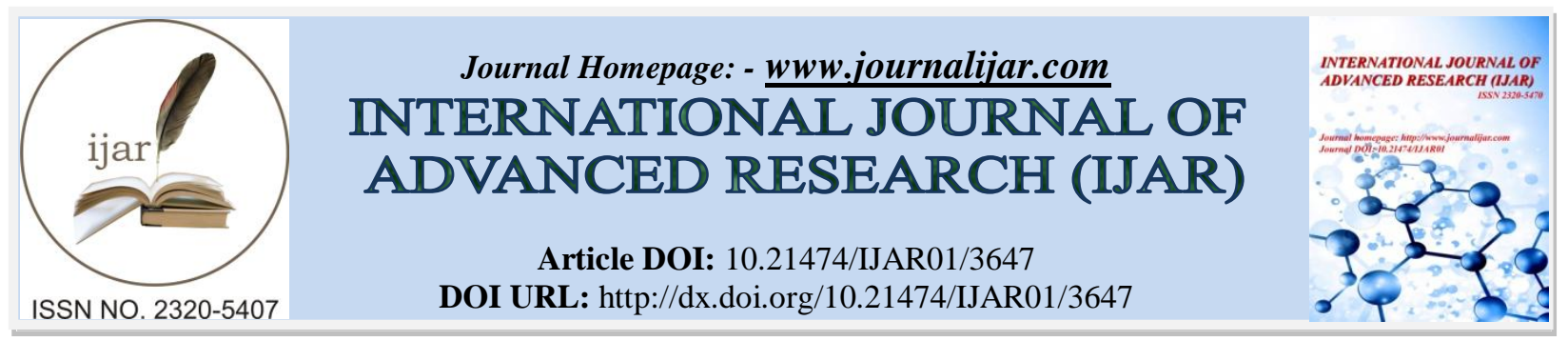

RESEARCH ARTICLE

\title{
EFFECT OF MUSIC AND PERSONALITY ON SEMANTIC MEMORY RETRIEVAL IN YOUNG ADULTS.
}

Asmita Karajgi ${ }^{1}$ and Krisha P. Shah ${ }^{2}$.

1. Professor and Head (Neurophysiotherapy), School Of Physiotherapy, D. Y. Patil University, Nerul, Navi Mumbai.

2. Intern, School Of Physiotherapy, D. Y. Patil University, Nerul, Navi Mumbai.

\section{Manuscript Info}

............................

Manuscript History

Received: 09 January 2017

Final Accepted: 06 February 2017

Published: March 2017

Key words:-

Semantic, Memory, retrieval, music, introvert, extrovert.

\section{Abstract}

Background -Listening to music while studying/working has been a commonly observed trait amongst youngsters. Effect of music and personality on short term memory and episodic memory has been studied but there is less evidence regarding the recall of semantic memory. Hence the purpose of the study was to explore the effect of different types of music and personality type on Semantic Memory Retrieval. Methods-In this cross-sectional study, asymptotic adults aged between 18-24yrs were administered a questionnaire to determine their personality type. Later, they were assessed on questions related to semantic memory recall in three different conditions namely; Silence, with Lyrical music and with Instrumental music. Total Time taken and the Total Score in all three conditions were analyzed. Conclusion- The mean of the Total Time and score was significantly more for Silence as compared to music condition. However they performed the fastest while instrumental music was played. There was no significant difference in Total Time as well as Total Score for both introverts and extroverts

Copy Right, IJAR, 2017,. All rights reserved.

\section{Introduction:-}

Memory gives us the ability to encode, store and recall information from our brain that helps us to function optimally. Semantic memory which is a part of explicit long term memory constitutes the knowledge of basic concepts or facts. It differs from the episodic memory related to the events ( Tulving, 1972). Psychologists describe semantic memory as the general knowledge/information one has acquired over a period of time. ( eg. Mumbai is in India, milk is white in colour etc.)Semantic memory is necessary while using language and a variety of cognitive activities. Recognition and use of objects includes association and combination of concepts, all of which are a part of the semantic memory. Thus it plays a crucial role in learning.

Review of literature suggests that music and type of personality are two important factors affecting memory recall in cognitive tasks. But the results are conflicting. Review of effect of background music on learning showed inconsistent findings ( Scholz D.,2011).A autobiographical memory recall in patients with dementia concluded that both familiar and non familiar music facilitated memory retrieval. (Foster NA and Valentine ER, 2001) But a study on Recall of word list suggested that encoding stage was influenced by music but not recall ( Konantz E.,2012).Later another study stated that music has a negative effect on recall of words and not digits. (Jameson C., 2013).Similarly personality traits also showed influence on memory recall. Music was found distracting for introverts and extroverts 
performing cognitive tasks and introverts performed the cognitive tasks worse than extroverts in presence of music. (Furnham \& Bradley, 1997, Furnham 2002)But complexity of music had not much effect on word memory task in introverts and extroverts(Matias L, 2014).Thus the evidence is more on short term memory and episodic (autobiographical) memory. However there is lack of clear understanding of effect of music and personality on semantic memory retrieval.

Today, music has become an integral part of the youngsters' lives in metropolitan city like Mumbai in India. Even while studying/working, people tend to listen to music. Some of them listen to lyrical music while others prefer instrumental music. Hence the objective of our study was to assess the effect of lyrical and instrumental music and personality on semantic memory retrieval in young adults.

\section{Material \& Methods:-}

Approval of the study was obtained from the Institutional Research Committee. This cross-sectional study was conducted during 4 months (from November 2015 to February 2016) at various colleges in Mumbai and Gujarat. Asymptomatic adults, with level of education above Grade 10, fluency in English language and with intact vision and hearing ability were eligible to participate. Any person with known musculoskeletal, neurological or psychiatric illness or with absence of vision and hearing ability were excluded from this study. A total of 111 participants were a part of this study. The study included the individuals in the age group of 18-24yrs.

After taking informed consent, the basic information was collected including participant's preference to listening to music, their mode of listening to music and the type of music they preferred to hear. Short-scale Eysenck Personality Questionnaire - Revised (Short-scale EPQ-R) was administered and the psychologist determined the personality type of each participant.

The participants were made to answer 3 sets of 15 questions each, in 3 different conditions, namely in silence, when lyrical music was played and when instrumental music was played. High-tempo lyrical music was chosen as one of the condition. The low-tempo instrumental music was chosen as the second condition. All the questions in the test were validated by a psychologist. The participants were instructed to write the answers on blank sheets which were provided to them. The questions were based on information stored in semantic memory. Although each question was different in all 3 sets, the basic criteria remained the same. For example, if one question was 'Which is the $5^{\text {th }}$ month of the year, in the other set the question would be 'Which is the $7^{\text {th }}$ month of the year?'.

The questions were displayed on a computer/laptop screen. Music was played over a headphone. For the lyrical music, a high tempo popular hindi movie song (Sooraj dooba hain from movie Roy) was chosen. For the instrumental music a low tempo song( relaxdaily $\mathrm{N}^{\circ} 062$ )was chosen. The same set of songs was played for each subject. The same headphone was used for everyone. The volume of the songs was also constant for every subject. The sequences of all 3 set of questions were also shuffled amongst all the participants.

For each subject, the time taken for them to complete each of the questionnaire and their score in all three conditions were analysed.

Result:-

Table I:- Demographic Characteristics.

\begin{tabular}{|l|l|}
\hline Characteristics & Total participants $(\mathrm{n}=111)$ \\
\hline Age (year) & $20.73($ mean) \\
\hline Gender ( M: F) & $41: 70$ \\
\hline Dominance (R:L) & $91: 9$ \\
\hline Personality traits & Extroverts 72 \\
& Introverts 39 \\
\hline $\begin{array}{l}\text { Preference to listening to music while } \\
\text { studying/working }\end{array}$ & Yes : 65 \\
\hline Mode of listening $(\%) *$ & ho $: 46$ \\
\hline Type of music preference* $(\%)$ & Lyrical : 80 \\
& Instrumental : 20 \\
\hline *For the ones who preferred listening to music while studying/working $(\mathrm{n}=65)$ \\
\hline
\end{tabular}


Table II:- Comparison of time and score of all participants across 3 conditions(silence,lyrical \&instrumental) .

\begin{tabular}{|c|c|c|c|}
\hline & Mean \pm SD & Mean \pm SD & p value \\
\hline & Silence & Lyrical & $0.01^{*}$ \\
\hline Time (sec) & $404.43 \pm 108.74$ & $365.55 \pm 92.36$ & 0.06 \\
\hline Score (Out of 38) & $32.66 \pm 3.00$ & $31.65 \pm 3.34$ & p value \\
\hline & Silence & Instrumental & $0.001^{*}$ \\
\hline Time (sec) & $404.43 \pm 108.74$ & $346.04 \pm 90.99$ & p value \\
\hline Score (Out of 38) & $32.66 \pm 3.00$ & $31.28 \pm 3.60$ & 0.11 \\
\hline \multicolumn{2}{|c|}{ Lyrical } & Instrumental & 0.42 \\
\hline Time (sec) & $365.55 \pm 92.362$ & $346.04 \pm 90.99$ & $31.28 \pm 3.60$ \\
\hline Score (Out of 38) & $31.65 \pm 3.34$ & SD, Standard Deviation; Statistical calculation and comparison between the groups by Kruskal-Wallis Test \\
(Nonparametric ANOVA) and Dunn's Multiple Comparisons Test; $*$ p value <0.05, considered significant
\end{tabular}

Statistical analysis shows that the mean of the Total Time was significantly more for Silence as compared to Instrumental music condition as well as for the Lyrical music condition.For the Total Score, mean in Silence was significantly more as compared to Instrumental music condition.

Table III:- Comparison of time and score between Introverts and Extroverts.

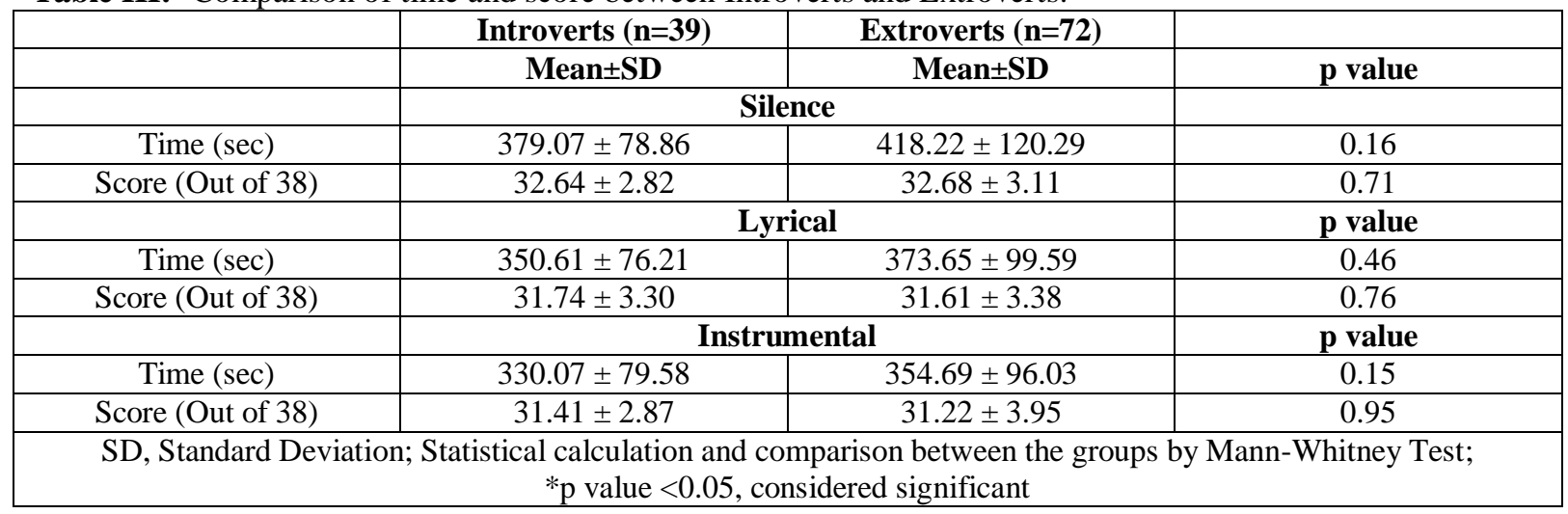

On comparing the mean values of Total Time and Total Score between introverts and extroverts in each condition, the two-tailed $\mathrm{P}$ value was considered not significant.

\section{Discussion:-}

On comparing the semantic memory recalling capacity in three different conditions, it was found that participants took the longest to complete the questionnaire in silence but scored the best in it. Thus the result of the present study showed that silence is the best environment for studying/working. We observed that the participants were able to focus more readily as there was least amount of distraction around while they performed in silence. This is in agreement with the previous studies on cognitive tasks where participants performed best in silence( Furnham \& Bradley, 1997, Konantz E, 2012,Jameson C, 2013).

In both the music conditions, time taken to complete the test was shorter compared to silence.But the scores dropped when music was played as compared to the scores in silence. When comparison was made between lyrical music condition and instrumental music condition, participants performed better when lyrical music was played. A previous study also showed that word recall was better when vocal music was played as compared to when instrumental music was played(Jameson C,2013).

In the current study, we did not test just the word recall but tested the conceptual knowledge. The test included various domains like knowledge about living, non living things as well as their visual and non visual attributes. It has been found that there are different areas in brain that get activated in memory retrieval(Martin A. et al.1995,2001, Thompson-Schill et al, 1999,2003 Martin A. 2007). There is a structured system along a posteroanterior axis in the temporal cortex, anterior temporal lobe being responsible for abstract knowledge and generalisation.(Roger T.T.et al 2006 ,Yee E.et al 2013) Memory and music possess a unique connection as the 
auditory processing area is also present in the temporal lobe. A PET study revealed that the verbal and musical semantic processes activated a common network extending throughout the left temporal neocortex. (Groussard et al., 2010) Hence it is difficult for one to perform the memory recall to their optimum level with music.

Based on the Short-scale Eysenck Personality Questionnaire - Revised, each participant was classified as being an introvert or an extrovert (Eysenck, S. B.1985) In the participants, 35\% were introverts and 65\% were extroverts. Introverts performed the best during silence and worst when instrumental music was played which is in agreement with previous studies. But in our study, extroverts also performed the best during silence and worst when instrumental music was played, thereby differing with the results of previous studies. (Furnham \& Bradley, 1997, Mistry H.2015)The reason behind this varied result may be because the tasks in the previous studies involved working memory whereas this study demanded recall from long term part of the memory.

The study suggests that silence is the best kind of environment one can study/work in as it aids in maximum semantic memory retrieval for majority of the individuals. For both introverts and extroverts as well, silence is the best environment to be preferred while studying/working. Even if the time required was more in silence in the present study, the difference was very less in terms of minutes.

Further research should be done by investigating semantic memory recall on the basis of the preference of the participants to listening to music while they study/work as well as when music is played in the background versus when it is played over headphones.

\section{References:-}

1. Eysenck, S. B., Eysenck, H. J., \& Barrett, P. (1985). A revised version of the psychoticism scale. Personality and individual differences, 6(1), 21-29.

2. Foster, N. A., \& Valentine, E. R. (2001). The effect of auditory stimulation on autobiographical recall in dementia. Experimental aging research, 27(3), 215-228.

3. Furnham, A., \& Bradley, A. (1997). Music while you work: The differential distraction of background music on the cognitive test performance of introverts and extraverts. Applied cognitive psychology, 11(5), 445-455.

4. Furnham, A., \& Strbac, L. (2002). Music is as distracting as noise: the differential distraction of background music and noise on the cognitive test performance of introverts and extraverts. Ergonomics, 45(3), 203-217.

5. Groussard, M., Viader, F., Hubert, V., Landeau, B., Abbas, A., Desgranges, B., ... \& Platel, H. (2010). Musical and verbal semantic memory: two distinct neural networks?. Neuroimage, 49(3), 2764-2773.

6. Jameson C.(2013)The Effect of Music on Recall Ability of Words and Digits ,DBS School of Arts, Dublin.

7. Konantz, E. (2012). The Effects of Music on Memory for a Word List. The Huron University College Journal of Learning and Motivation, 50(1), 4.

8. Martin, A., \& Chao, L. L. (2001). Semantic memory and the brain: structure and processes. Current opinion in neurobiology, 11(2), 194-201.

9. Martin, A., Haxby, J.V., Lalonde, F. M., Wiggs, C. L., \& Ungerleider, L.G. (1995). Discrete cortical regions associated with knowledge of color and knowledge of action. Science, 270, 102-105.

10. Martin, A. (2007) The representation of object concepts in the brain.Annual Review of Psychology, 58, 25-45

11. Matias, L. (2014). The Effects of Music Complexity on Memory in Introverts and Extroverts. The Huron University College Journal of Learning and Motivation, 52(1), 10.

12. Mistry, H. (2015). Music while you work: the effects of background music on test performance amongst extroverts and introverts. Journal of Applied Psychology and Social Science, 1(1), 1-14.

13. Rogers, T. T., Hocking, J., Noppeney, U., Mechelli, A., Gorno-Tempini,M., Patterson, K. and Price, C. (2006). The anterior temporal cortex and semantic memory: Reconciling findings from neuropsychology and functional imaging. Cognitive, Affective and Behavioral Neuroscience, 6, 201-213

14. Scholz D. (2011) The Effect of Background Music on Learning,theis, Universiteit van Amsterdam.

15. Thompson-Schill, S.L. (2003). "Neuroimaging studies of semantic memory: inferring "how" from "where"". Neuropsychologia. 41 (3): 280-292.

16. Thompson-Schill, S. L, Aguirre, G. K., D’Esposito, M., \& Farah, M. J.(1999). A neural basis for category and modality specificity of semantic knowledge. Neuropsychologia, 37, 671-676

17. Tulving, E. (1972). Episodic and Semantic Memory: Organization of Memory (E. Tulving \& W. Donaldson ed.). New York, NY: Academic Press. pp. 382-403.

18. Yee, E., Chrysikou, E. G., \& Thompson-Schill, S. L. (2013). The cognitive neuroscience of semantic memory. The Oxford handbook of cognitive neuroscience, 1, 353-374. 